\title{
Influence of DAP1 Genotype and Psychosocial Factors on Posttraumatic Stress Disorder in Thai Tsunami Survivors: A GxE Approach
}

\author{
Nuntika Thavichachart ${ }^{*}$, Prathan Rutchatajumroon2 ${ }^{2}$, Taisei Mushiroda ${ }^{3}$, \\ Anchalee Prasansuklab4, Sookjaroen Tangwongchai', Puangsoi Worakul', \\ Buranee Kanchanatawan', Siriluck Suppapitiporn', Atapol Sughondhabirom1, \\ Chutima Roomruangwong ${ }^{1}$, Thongchai Thavichachart ${ }^{2}$, Ongart Charoensook ${ }^{2}$, \\ Wasun Chantratita ${ }^{5}$, Atsushi Takahashi ${ }^{6}$, Michiaki Kubo ${ }^{7}$, Naoyuki Kamatani ${ }^{6}$, \\ Yusuke Nakamura ${ }^{8}$

\footnotetext{
${ }^{1}$ Department of Psychiatry, Faculty of Medicine, Chulalongkorn University, Bangkok, Thailand

${ }^{2}$ Thailand Center of Excellence for Life Sciences (Public Organization), Ministry of Science and Technology, Bangkok, Thailand ${ }^{3}$ Laboratory for Pharmacogenetics, RIKEN Center for Genomic Medicine, Kanagawa, Japan

${ }^{4}$ College of Public Health Sciences, Chulalongkorn University, Bangkok, Thailand

${ }^{5}$ Center for Medical Genomics, Ramathibodi Hospital, Mahidol University, Bangkok, Thailand

${ }^{6}$ Laboratory for Statistical Analysis, RIKEN Center for Genomic Medicine, Kanagawa, Japan

${ }^{7}$ Laboratory for Genotyping Development, RIKEN Center for Genomic Medicine, Kanagawa, Japan

${ }^{8}$ Laboratory of Molecular Medicine, Human Genome Center, Institute of Medical Science, The University of Tokyo, Tokyo, Japan

Email: *nuntika.th@gmail.com
}

How to cite this paper: Thavichachart, N., Rutchatajumroon, P., Mushiroda, T., Prasansuklab, A., Tangwongchai, S., Worakul, P., Kanchanatawan, B., Suppapitiporn, S., Sughondhabirom, A., Roomruangwong, C., Thavichachart, T., Charoensook, O., Chantratita, W., Takahashi, A., Kubo, M., Kamatani, N. and Nakamura, Y. (2019) Influence of DAP1 Genotype and Psychosocial Factors on Posttraumatic Stress Disorder in Thai Tsunami Survivors: A GxE Approach. Open Journal of Genetics, 9, 65-75.

https://doi.org/10.4236/ojgen.2019.93005

Received: March 25, 2019

Accepted: September 1, 2019

Published: September 4, 2019

\begin{abstract}
Background: Posttraumatic Stress Disorder (PTSD) is a psychiatric disorder found in individuals afflicted by a traumatic event including the natural disaster. "Tsunami" occurred in Andaman coast of Thailand on December 26, 2004 , in which $33.6 \%$ of survivors were diagnosed as PTSD. This study aimed to explore the single nucleotide polymorphism (SNP). rs267943 genotype is located on chromosome 5 in the intron of the death-associated protein 1 (DAP1) gene and psychosocial factors for PTSD. Methods: Participants $(\mathrm{N}=$ 1970) were recruited from volunteers who have complete data both of DAP1 gene and psychosocial factor. Results: Using a binary logistic regression model, significant gene-environment interactions were found for the single nucleotide polymorphism (SNP) rs267943 and psychosocial factors including depression (adj. OR $=6.0,95 \% \mathrm{CI}=4.29-8.39$ ), neurotic personality (adj. $\mathrm{OR}=2.73,95 \% \mathrm{CI}=2.18-3.42$ ), planning (adj. $\mathrm{OR}=1.52,95 \% \mathrm{CI}=1.20$ 1.93 ), use of emotional support (adj. $\mathrm{OR}=1.32,95 \% \mathrm{CI}=1.21-1.94)$ with statistical significant $\mathrm{p}<0.001$ and self-distraction $(\operatorname{adj} . \mathrm{OR}=1.52,95 \% \mathrm{CI}=$ 1.15 - 1.85) with statistical significant $p<0.05$. Conclusion: This study dem-
\end{abstract}


Copyright (C) 2019 by author(s) and Scientific Research Publishing Inc. This work is licensed under the Creative Commons Attribution International License (CC BY 4.0). http://creativecommons.org/licenses/by/4.0/ onstrated that GxE studies can be utilized to shed light on the origins of PTSD.

\section{Keywords}

Death-Associated Protein 1 Gene (DAP1), Gene-by-Environment Interaction (GxE), Genetype, Posttraumatic Stress Disorder (PTSD), Psychosocial

Factors, Tsunami

\section{Introduction}

Acute Stress Disorder (ASD) is one of the forms of traumatic stress which can be developed immediately, following exposure to a traumatic stressor, including, natural disasters. Survivors experience unwanted, uncontrollable memories of the event that gave rise to physical and emotional responses. When the symptoms with intrusion, avoidance and hyperarousal persist for a month, individuals with ASD will subsequently develop posttraumatic stress disorder (PTSD). Re-experiencing traumatic events, emotional avoidances, mood swings and increased arousals are the characteristics of PTSD. The prevalence of the PTSD ranges from $\sim 0 \%$ to $50 \%$, depending on the type of traumatic events, social economic status, environmental stressors and genotypic makeups.

Although etiology and pathogenesis of PTSD are not clear to date, evidence implies that the development of the PTSD can be influenced by both genetic and environmental factors. Substantial progress has been made in the area of psychiatric genetics in which previously reported loci, including ANKRD55 [1], PRTFDC1 [2], lincRNA AC068718.1 [3], ADCYAP1R1 [4], RORA [5] have been identified for PSTD. In fact, there is a shared genetic which influences between PTSD and other psychiatric disorders, indicating the potential genetic risk with PTSD [6]. On the other hand, distinct environmental factors that are not shared by all PTSD patients are responsible for pathogenesis of PTSD disorder including serious road accidents, violent personal assaults, traumatic births, prolonged sexual abuses, witnessing violent deaths, military combats, being held hostages, terrorist attacks, natural disasters, diagnosis of a life-threatening condition and an unexpected severed injuries or deaths of a close family member or friend. The severity of PTSD is associated with violence exposures, substance abuses, environmental threats, sexual abuses, combat traumas and tsunami [7]. Twin studies have suggested that both genetic and environmental factors influence risk for PTSD, suggesting the interplay between genetic and environmental factors in psychiatric disorders [8]. Thus, the presence of psychiatric disorders may be associated with both psychosocial and genetic factors that contribute to the aetiology of PTSD symptoms.

Single nucleotide polymorphism (SNP) of the death-associated protein 1 (DPA1) gene have been associated with apoptosis [9] and autophagy [10], implicating in the pathogenesis of several neurodegenerative disorders [11]. Tha- 
vichachart et al. [12] undertook for the first time construction of Genome-wide association study (GWAS) for PTSD susceptibility in an Asian population. Such GWAS studies represent an ideal approach for discerning genetic contribution to PTSD. Several studies have been done to determine the risk and resiliency factors for PTSD, which has been linked with genetic polymorphism of nervous system development [13], Bax functional polymorphisms [14] and genetic polymorphism of 5-HTTLPR [15]. Given that expected variance contributed by any single genetic factor is small [16], studies incorporating the effects of the environment, including psychosocial factors are desirable.

Gene-environment interaction $(\mathrm{GxE})$ occurs when the effect of exposure to an environmental factors (e.g., Natural Disaster). The understanding that both genes (nature) and environments (nurture) are important for understanding the origins of PTSD has led to rapid growth in research exploring gene-environment interaction $(\mathrm{GxE})$. In this context, psychosocial factors, including depression comorbid, direct affected area, physical injury, planning copies, use of emotional support coping, self-distraction, coping, denial coping and neurotic personality may reflect the impact on the severity of PTSD.

The comparatively limited research has that been undertaken to date on the association between genotype and psychosocial factors, subsequent Tsunami occurrence in Thailand. Therefore, in the study, we performed a GxE study to investigate the interaction between a series of gene and a series of environmental factors. Such approach present methodological give a better understanding of the mechanism on the development of PTSD which may aid in PTSD prevention and therapeutic treatment.

\section{Methods}

\subsection{Participants and Procedures}

All of the participants were over the age of 18 years old, and parental consent was therefore deemed unnecessary. A cross-sectional community survey was conducted among Thai population residing in Pang-Nga, Ranong Phuket, Krabi, Trang and Satoon, six provinces in the southern part of Thailand that had been affected by Tsunami. To better examine how genetic factors can influence the development of PTSD, only Thai subject having at least 3 generations of southeast Asian ancestor was considered, minimizing the problem of multiple ancestries in the studied population. The chronic PTSD cases used in this study were selected who suffered from PTSD longer than six months whereas subjects that are not affected with PTSD at least six months of aftermath were defined as controls. Participants having severe physical and mental conditions, which hinder communication during the interviewing process are subjected to removal.

\subsection{Measure Scales}

Two stages of community surveys were conducted. The first of Thai population age 18 and above from affected and controlled area were collected by using de- 
mographic and psychosocial questionnaires consisting of Davison Trauma Scale (DTS), Beck II Depression Inventory (BDI-II), Hopkins' Symptom Check List 90 (SCL90), Maudsley Personality Inventory (MPI) and Brief Cope Scale (BCS) are used as a measure scales to find out the prevalence of PTSD and correlated psychosocial affected [17].

In the second phase we interviewed PTSD cases and controls to find chronic PTSD by Semi-Structured Assessment for Drug Dependence and Alcoholism (SADDA) followed by composite international diagnostic interview (CIDI) to determine co-morbidity and to exclude other psychological disorders including drug abused, bipolar and anxiety disorders, according to the definitions of the Diagnostic Criteria for Research of ICD-10 and DSM-III-R. Blood samples were collected and DNA was extracted for genetic study [12].

DTS is the commonly used as a screening test for PTSD, composed of 17 items corresponding to each of the symptom definitions of the Diagnostic and Statistical Manual of Mental Disorders, $4^{\text {th }}$ edition (DSM-IV) and shown to have good test-retest reliability and internal consistency [18]. The BDI has great clinical utility and to assess the severity of depression and display reliable psychometrics characteristics across a broad spectrum of the population [19]. SCL90 is a 90 -item symptom inventory designed for patient self-report of psychosocial symptoms which can be used to rate mode and physical well-being [20]. MPIis a questionnaire designed to measure neuroticism having re-test reliability of greater than 0.8 [21]. The BCS is commonly used the scale to measure a broad range of coping responses with a good reliability and validity, containing 28 items and rated by the four-point like scales [22].

\subsection{Genotyping and Assessing Transcriptional Activity}

DAP1 genotyping was performed and validated using previously described conditions and methods [12]. Genomic DNA was extracted from peripheral blood leucocytes and prepared for genotyping. Genotyping for DAP1 was carried out using Illumina Human-Hap610 Genotyping BeadChip. After removal of SNP located on mitochondrial DNA or on X and Y chromosomes, a second GWAS was performed by resequencing relevant region with BigDye Terminator cycle sequencing kit and a 96-capillary 3730xl DNA Analyzer.

The transcriptional activity of rs267943 was assessed using the luciferase assay. The SNP rs267943 is located within DAP1 on chromosome 5. The strongest signal for association with PTSD susceptibility was observed in rs267943 which achieved a genome-wide significant level $\left(\mathrm{MH}-P=6.15 \times 10^{-8}\right)$, the risk allele "G" and non-risk allele " $A$ ". Genotypic frequencies were as follows: A/A: 46.5\% $(\mathrm{n}=916) ; \mathrm{G} / \mathrm{G}: 10.1 \%(\mathrm{n}=199) ; \mathrm{A} / \mathrm{G}: 43.4 \%(\mathrm{n}=855)$.

\subsection{Data Analysis}

As to provide an overview of the data, both univariate and multivariate analysis were performed using standard statistical methods. Relationship between PTSD 
and dependent variables (characteristics) were identified using a chi-squared association test. Multivariate analysis was performed using Binary logistic regression analysis. The Univariate analysis was performed by using R statistical package and the latter was performed using SPSS software.

\section{Results}

A total number of 1970 samples were included in the study in which 1268 samples represent the control group whereas 702 samples were positive groups. As seen Table 1, the sample contains diverse age group for both cases and controls group, which seems to be equally distributed. A closer look at the data reveals that there is a significant difference between sex (Female $=63.5 \%$ and Male $=$ 36.5) for the cases groups. Recently, Duncan et al. examined 20,730 individuals and reported the prevalence of PTSD is higher in female than males [6]. This report is consistent with the molecular genetics of two study results in which heritability for PTSD is overall higher in females in males [23] [24] [25] [26]. On average, the mean age of both samples is $\sim 39.84$ with \pm 13.85 years. After binning the age of samples into the 4 age group ( $\leq 28,29-37,38-48, \geq 49)$, both control and cases sample are equally distributed in each category as seen in Figure 1.

Table 1. Sample characteristics.

\begin{tabular}{|c|c|c|c|c|}
\hline \multirow{3}{*}{ Characteristics } & \multicolumn{2}{|c|}{ Sample with PTSD } & \multicolumn{2}{|c|}{ Statistics } \\
\hline & Controls $(n=1268)$ & Cases $(n=702)$ & \multirow{2}{*}{$x^{2}$} & \multirow{2}{*}{$p$} \\
\hline & $\mathrm{n}(\%)$ & $\mathrm{n}(\%)$ & & \\
\hline \multicolumn{5}{|l|}{ Gender } \\
\hline Female & $735(58.0)$ & $446(63.5)$ & 5.83 & $0.016^{*}$ \\
\hline Male & $533(42.0)$ & $256(36.5)$ & & \\
\hline \multicolumn{5}{|l|}{ Age (yrs.) } \\
\hline$\leq 28$ & $279(22.0)$ & $177(25.2)$ & 12.75 & $0.005^{\star *}$ \\
\hline $29-37$ & $296(23.3)$ & $181(25.8)$ & & \\
\hline $38-48$ & $346(27.3)$ & $202(28.8)$ & & \\
\hline$\geq 49$ & $347(27.4)$ & $142(20.2)$ & & \\
\hline \multicolumn{5}{|c|}{ Mean $=39.84, \mathrm{SD}=13.85 \mathrm{yrs}$} \\
\hline \multicolumn{5}{|l|}{ Marital Status } \\
\hline single & $173(13.6)$ & $74(10.5)$ & 5.024 & 0.081 \\
\hline married & $975(76.9)$ & $569(81.1)$ & & \\
\hline divorced/widowed & $120(9.5)$ & $59(8.4)$ & & \\
\hline \multicolumn{5}{|l|}{ Educational Status } \\
\hline illiterate & $27(2.1)$ & $10(1.4)$ & 2.86 & 0.581 \\
\hline elementary school & $810(63.9)$ & $470(67.0)$ & & \\
\hline primary school & $207(16.3)$ & $111(15.8)$ & & \\
\hline secondary school & $178(14.1)$ & $89(12.7)$ & & \\
\hline academic degree & $46(3.6)$ & $22(3.1)$ & & \\
\hline
\end{tabular}




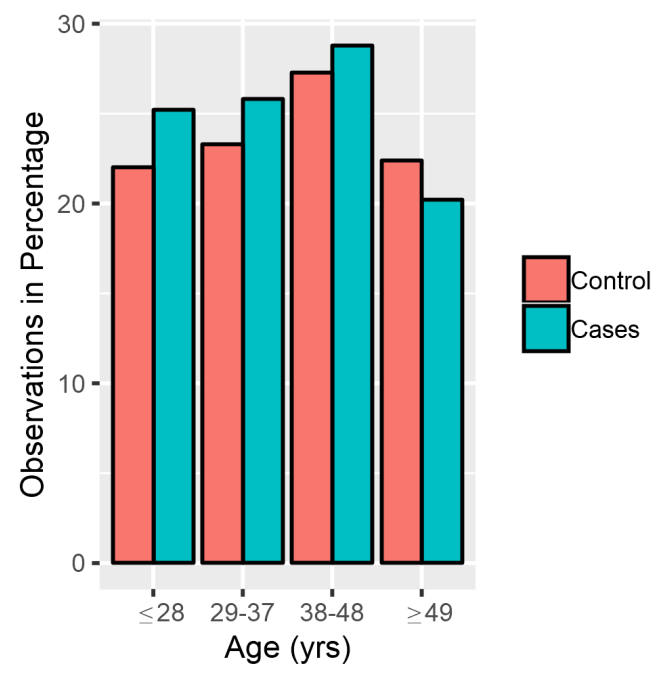

Figure 1. Color-coded bar plot showing the distribution of sample across different groups for both Control and Cases.

The relationship between the PTSD status and effect of age are tested in which age can significantly predict PTSD in univariate analysis $(\mathrm{p}<0.05)$.

There are conflicting findings which have been reported in association studies on PTSD genotype. Hovhannisyan et al. studies showed significant decreased risk of rs16944A with PTSD susceptibility, indicating that homozygous individuals have a decreased risk of PTSD compared to heterozygotes [27]. In addition, Parade et al. reported that homozygotes AA genotype is associated with decreased methylation of HTR2A [28]. On the other hand, Conrad et al. claimed homozygous AA genotype have a higher risk of PTSD than heterozygotes in the Ugandan cohort [29]. To add to this debate, we have performed SNP of rs267943 genotype for association with PTSD diagnosis.

Table 2 shows the results of the genotyping found within PTSD in which the rate of PTSD is higher among $\mathrm{G}$ allele heterozygotes i.e., A/G (47.4\%) when compare with A homozygotes (39.2\%) and G homozygotes (13.4\%).

To test for possible GxE effects between genetic factor and environment factor as well as the psychosocial factor, logistic regression models were utilized. This is to shed insights on the effect of DAP1 on PTSD after accounting for the influence of physical injury, affected area, coping, personality and comorbid. A significant additive effect can be seen for DAP1 Gene among Tsunami survivor, such that the odds of having a current diagnosis of PTSD increased by 1.43 for each additional G' allele. Environmental factors, including directed affected area and physical injury, also had significant effects on risk for PTSD in the logistic regression model. In addition, significant effects obtained from the combination of the DAP1 gene with depression (adj. OR $=6.0,95 \% \mathrm{CI}=4.29-8.39, \mathrm{p}<$ 0.001 ), neurotic personality (adj. $\mathrm{OR}=2.73,95 \% \mathrm{CI}=2.18-3.42, \mathrm{p}<0.001$ ), planning (adj. $\mathrm{OR}=1.52,95 \% \mathrm{CI}=1.20-1.93, \mathrm{p}<0.001$ ), use of emotional support (adj. OR $=1.32,95 \% \mathrm{CI}=1.21-1.94, \mathrm{p}<0.001$ ) and self-distraction 
Table 2. The SNP rs267943 genotype.

\begin{tabular}{cccc}
\hline \multicolumn{4}{c}{ PTSD } \\
\hline rs267943 & Controls & Cases & Total \\
\cline { 2 - 4 } Genotype & $\mathrm{n}(\%)$ & $\mathrm{n}(\%)$ & $\mathrm{n}(\%)$ \\
\hline Allele & & & \\
A/A & $641(50.6)$ & $275(39.2)$ & $916(46.5)$ \\
G/G & $105(8.3)$ & $94(13.4)$ & $199(10.1)$ \\
A/G & $522(41.1)$ & $333(47.4)$ & $855(43.4)$ \\
\hline
\end{tabular}

(adj. OR $=1.52,95 \% \mathrm{CI}=1.15-1.85, \mathrm{p}<0.05)$. The findings in Table 3 showed that all variables have significant at $5 \%$ significant level, while depression, personality, use of emotional support, planning, directed affected area showed the significant level at $1 \%$.

\section{Discussion}

The prevalence of the PTSD in the Asian population is $33.5 \%$ after the tsunami occurrence in Andaman coast on Thailand in which age and gender are significant predictors of the PTSD status. This is in agreement with the previous reports from Nievergelt et al., which claimed that the age variable can significantly predict the PTSD status [2]. Ressler et al. also stated that there is a significant sex-specific association with PTSD status [4], indicating that sex hormones, oestrogen, may have implicational roles in developing disorder [30].

We have also shown that the DAP1 gene has the strongest signal for association with PTSD susceptibility. Indeed, DAP1 gene is involved in mediating interferon-gamma-induced cell death via activation of caspases and NF-kappaB. NF-kappaB, the G-protein-coupled receptor (GPCR) pathway molecule, can promote or prevent substain depressive-life behavior following severe stress (Nuclear factor-kappaB is a critical mediator of stress-impaired neurogenesis and depressive behavior). Interestingly, it was reported that mRNA levels of NFkappB are upregulated in monocytes in PTSD patient, explaining how DAP1 is involved in signaling pathway to implicate in depressive-like behavior and their potential contribution to the etiology of PTSD. In addition, DAP1 gene was also reported to the substrate of the mTor.

Strength of the current study includes 1) the continuous use of sample since 2004 Tsunami, increasing power to detect PTSD effects, 2) a tsunami-exposed cases and controls group included of only Thai subject to minimize the problem of multiple ancestries in study population, a well-defined clinical phenotype 3 ) and lastly consideration of complete variables to describe psychosocial and genetic factors to get a better picture on etiology and pathogenesis of PTSD. However, the limitation of the current study includes the use of DSM-IV criteria to define PTSD and failure to capture clinician-rated symptom severity ratings on all of the participants. Therefore, additional research on the potential relationship between DAP1, environmental and physiological factors as well as clinical-rated PTSD symptom severity among tsunami survivor is still needed. 
Table 3. Results obtained from the logistic regression.

\begin{tabular}{lccc}
\hline \multicolumn{1}{c}{ Variable } & Adjusted OR & $95 \% \mathrm{CI}$ & p-value \\
\hline $\begin{array}{l}\text { 1) Genetic Factor } \\
\text { DAP1 Gene, The SNP rs26794: Allele G }\end{array}$ & 1.43 & $1.15-1.79$ & 0.001 \\
& & & \\
2) Environment Factor & 2.90 & $2.29-3.68$ & 0.000 \\
a) direct affected area & 1.31 & $1.02-1.69$ & 0.030 \\
b) physical injury & & & \\
$\begin{array}{l}\text { 3) Psychosocial Factor } \\
\text { a) coping }\end{array}$ & 1.52 & $1.20-1.93$ & 0.000 \\
- planning & 1.53 & $1.21-1.94$ & 0.000 \\
- use of emotional support & 1.45 & $1.15-1.85$ & 0.002 \\
- self distraction & & & \\
b) personality & & & \\
- neurotic personality & 2.73 & $2.18-3.42$ & 0.000 \\
c) comorbid & & & \\
- depression & 6.00 & $4.29-8.39$ & 0.000
\end{tabular}

\section{Conclusion}

In conclusion, considerable evidence emphasizes the importance of both susceptibility gene and psychosocial factors contribution to the development of PTSD. This study supporsts these findings by reporting the GxE interaction in PTSD to identify psychosocial factors to PTSD susceptibility. Using a binary logistic regression model, significant gene-environment interactions were found for the single nucleotide polymorphism (SNP) rs267943 and psychosocial factors including depression (adj. OR $=6.0,95 \% \mathrm{CI}=4.29-8.39$ ), neurotic personality (adj. $\mathrm{OR}=2.73,95 \% \mathrm{CI}=2.18-3.42$ ), planning (adj. $\mathrm{OR}=1.52,95 \% \mathrm{CI}=1.20$ 1.93), use of emotional support (adj. $\mathrm{OR}=1.32,95 \% \mathrm{CI}=1.21-1.94$ ) with statistical significant $\mathrm{p}<0.001$ and self-distraction (adj. $\mathrm{OR}=1.52,95 \% \mathrm{CI}=1.15$ 1.85 ) with statistical significant $p<0.05$. These findings indicate potential mechanisms by which gene and environmental factors are associated with psychosocial factors with the emergence of PTSD, which will assist public health planning and treatment.

\section{Acknowledgements}

We would like to acknowledge the all staff in our team and all subjects who participated in this study. Funding for sample collection was provided by grants from Thailand Center of Excellence for Life Sciences (TCELS) and funding for genotyping was supported by RIKEN Yokohama Institute.

\section{Conflicts of Interest}

The authors declare no conflicts of interest regarding the publication of this paper. 


\section{References}

[1] Stein, M.B., Chen, C.-Y., Ursano, R.J., Cai, T., Gelernter, J., Heeringa, S.G., Jain, S., Jensen, K.P., Maihofer, A.X., Mitchell, C., et al. (2016) Genome-Wide Association Studies of Posttraumatic Stress Disorder in 2 Cohorts of US Army Soldiers. JAMA Psychiatry, 73, 695-704. https://doi.org/10.1001/jamapsychiatry.2016.0350

[2] Nievergelt, C.M., Maihofer, A.X., Mustapic, M., Yurgil, K.A., Schork, N.J., Miller, M.W., Logue, M.W., Geyer, M.A., Risbrough, V.B., O’Connor, D.T. and Baker, D.G. (2015) Genomic Predictors of Combat Stress Vulnerability and Resilience in US Marines: A Genome-Wide Association Study Across Multiple Ancestries Implicates PRTFDC1 as a Potential PTSD Gene. Psychoneuroendocrinology, 51, 459-471. https://doi.org/10.1016/j.psyneuen.2014.10.017

[3] Guffanti, G., Galea, S., Yan, L., Roberts, A.L., Solovieff, N., Aiello, A.E., Smoller, J.W., De Vivo, I., Ranu, H. and Uddin, M., et al. (2013) Genome-Wide Association Study Implicates a Novel RNA Gene, the LincRNA AC068718.1, as a Risk Factor for Post-Traumatic Stress Disorder in Women. Psychoneuroendocrinology, 38, 3029-3038. https://doi.org/10.1016/j.psyneuen.2013.08.014

[4] Ressler, K.J., Mercer, K.B., Bradley, B., Jovanovic, T., Mahan, A., Kerley, K., Norrholm, S.D., Kilaru, V., Smith, A.K., Myers, A.J., et al. (2011) Post-Traumatic Stress Disorder is Associated with PACAP and the PAC1 Receptor. Nature, 470, 492-497. https://doi.org/10.1038/nature09856

[5] Logue, M.W., Baldwin, C., Guffanti, G., Melista, E., Wolf, E.J., Reardon, A.F., Uddin, M., Wildman, D., Galea, S., Koenen, K.C. and Miller, M.W. (2013) A Genome-Wide Association Study of Post-Traumatic Stress Disorder Identifies the Retinoid-Related Orphan Receptor Alpha (RORA) Gene as a Significant Risk Locus. Molecular Psychiatry, 18, 937-942. https://doi.org/10.1038/mp.2012.113

[6] Duncan, L.E., Ratanatharathorn, A., Aiello, A.E., Almli, L.M., Amstadter, A.B., Ashley-Koch, A.E., Baker, D.G., Beckham, J.C., Bierut, L.J., Bisson, J., et al. (2018) Largest GWAS of PTSD (N= 20 070) Yields Genetic Overlap with Schizophrenia and Sex Differences in Heritability. Molecular Psychiatry, 23, 666-673. https://doi.org/10.1038/mp.2017.77

[7] Schottenbauer, M.A., Glass, C.R., Arnkoff, D.B., Tendick, V. and Gray, S.H. (2008) Nonresponse and Dropout Rates in Outcome Studies on PTSD: Review and Methodological Considerations. Psychiatry: Interpersonal and Biological Processes, 71, 134-168. https://doi.org/10.1521/psyc.2008.71.2.134

[8] Afifi, T.O., Asmundson, G.J., Taylor, S. and Jang, K.L. (2010) The Role of Genes and Environment on Trauma Exposure and Posttraumatic Stress Disorder Symptoms: A Review of Twin Studies. Clinical Psychology Review, 30, 101-112. https://doi.org/10.1016/j.cpr.2009.10.002

[9] Deiss, L.P., Feinstein, E., Berissi, H., Cohen, O. and Kimchi, A. (1995) Identification of a Novel Serine/Threonine Kinase and a Novel 15-kD Protein as Potential Mediators of the Gamma Interferon-Induced Cell Death. Genes \& Development, 9, 15-30. https://doi.org/10.1101/gad.9.1.15

[10] González-Estévez, C., Felix, D.A., Aboobaker, A.A. and Saló, E. (2007) Gtdap-1 Promotes Autophagy and Is Required for Planarian Remodeling during Regeneration and Starvation. Proceedings of the National Academy of Sciences, 104, 13373-13378. https://doi.org/10.1073/pnas.0703588104

[11] Vila, M. and Przedborski, S. (2003) Neurological Diseases: Targeting Programmed Cell Death in Neurodegenerative Diseases. Nature Reviews Neuroscience, 4, 365-375. https://doi.org/10.1038/nrn1100 
[12] Thavichachart, N., Mushiroda, T., Thavichachart, T., Charoensook, O., Prasansuklab, A., Rutchatajumroon, P., Tangwongchai, S., Worakul, P., Kanchanatawan, B., Suppapitiporn, S., et al. (2015) Genome-Wide Association Study in Thai Tsunami Survivors Identified Risk Alleles for Posttraumatic Stress Disorder. Open Journal of Genetics, 5, 43-57. https://doi.org/10.4236/ojgen.2015.52004

[13] Avetyan, D., Arakelyan, A. and Mkrtchyan, G. (2018) Genetic Polymorphisms of Nervous System Development and the Risk of Posttraumatic Stress Disorder. American Journal of Molecular Biology, 8, 58-68. https://doi.org/10.4236/ajmb.2018.81005

[14] Avetyan, D., Arakelyan, A. and Mkrtchyan, G. (2018) Association of Bax and Bcl-2 Functional Polymorphisms and Protein Levels with Posttraumatic Stress Disorder. Journal of Biosciences and Medicines, 6, 23-32. https://doi.org/10.4236/jbm.2018.62003

[15] Jiang, X.L. and Guo, J.C. (2016) A Associated Research for Genetic Polymorphism of 5-Httlpr with Posttraumatic Stress Disorder: P0223. International Journal of Psychology, 51, 132.

[16] Committee, P.G.C.C. (2009) Genomewide Association Studies: History, Rationale, and Prospects for Psychiatric Disorders. The American Journal of Psychiatry, 166, 540-556. https://doi.org/10.1176/appi.ajp.2008.08091354

[17] Thavichachart, N., Tangwongchai, S., Worakul, P., Kanchanatawan, B., Suppapitiporn, S., Na Pattalung, A.S., Roomruangwong, C. and Chareonsook, O. (2009) Posttraumatic Mental Health Establishment of the Tsunami Survivors in Thailand. Clinical Practice and Epidemiology in Mental Health, 5, 11.

https://doi.org/10.1186/1745-0179-5-11

[18] Davidson, J.R.T., Tharwani, H.M. and Connor, K.M. (2002) Davidson Trauma Scale (DTS): Normative Scores in the General Population and Effect Sizes in PlaceboControlled SSRI Trials. Depression and Anxiety, 15, 75-78. https://doi.org/10.1002/da.10021

[19] Beck, A.T., Steer, R.A., Ball, R. and Ranieri, W.F. (1996) Comparison of Beck Depression Inventories-IA and-II in Psychiatric Outpatients. Journal of Personality Assessment, 67, 588-597. https://doi.org/10.1207/s15327752jpa6703_13

[20] Pichot, P. and Olivier-Martin, R. (1974) Psychological Measurements in Psychopharmacology. Karger, Switzerland.

[21] Eysenck, H.J. (1958) Manual of the Maudsley Personality Inventory. University of London Press, London. https://doi.org/10.1037/t17867-000

[22] Yusoff, N., Low, W. and Yip, C. (2010) Reliability and Validity of the Brief COPE Scale (English Version) among Women with Breast Cancer Undergoing Treatment of Adjuvant Chemotherapy: A Malaysian Study. Medical Journal of Malaysia, 65, 41-44.

[23] Wolf, E.J., Mitchell, K.S., Koenen, K.C. and Miller, M.W. (2014) Combat Exposure Severity as a Moderator of Genetic and Environmental Liability to Post-Traumatic Stress Disorder. Psychological Medicine, 44, 1499-1509. https://doi.org/10.1017/S0033291713002286

[24] Sartor, C.E., McCutcheon, V., Pommer, N., Nelson, E., Grant, J., Duncan, A., Waldron, M., Bucholz, K., Madden, P. and Heath, A. (2011) Common Genetic and Environmental Contributions to Post-Traumatic Stress Disorder and Alcohol Dependence in Young Women. Psychological Medicine, 41, 1497-1505. https://doi.org/10.1017/S0033291710002072

[25] Stein, M.B., Jang, K.L., Taylor, S., Vernon, P.A. and Livesley, W.J. (2002) Genetic 
and Environmental Influences on Trauma Exposure and Posttraumatic Stress Disorder Symptoms: A Twin Study. American Journal of Psychiatry, 159, 1675-1681. https://doi.org/10.1176/appi.ajp.159.10.1675

[26] True, W.R., Rice, J., Eisen, S.A., Heath, A.C., Goldberg, J., Lyons, M.J. and Nowak, J. (1993) A Twin Study of Genetic and Environmental Contributions to Liability for Posttraumatic Stress Symptoms. Archives of General Psychiatry, 50, 257-264.

https://doi.org/10.1001/archpsyc.1993.01820160019002

[27] Hovhannisyan, L., Stepanyan, A. and Arakelyan, A. (2017) Genetic Variability of Interleukin-1 Beta as Prospective Factor from Developing Post-Traumatic Stress Disorder. Immunogenetics, 69, 703-708. https://doi.org/10.1007/s00251-017-1016-4

[28] Parade, S.H., Novick, A.M., Parent, J., Seifer, R., Klaver, S.J., Marsit, C.J., Gobin, A.P., Yang, B.-Z. and Tyrka, A.R. (2017) Stress Exposure and Psychopathology Alter Methylation of the Serotonin Receptor 2A (HTR2A) Gene in Preschoolers. Development and Psychopathology, 29, 1619-1626.

https://doi.org/10.1017/S0954579417001274

[29] Conrad, D., Wilker, S., Schneider, A., Karabatsiakis, A., Pfeiffer, A., Kolassa, S., Freytag, V., Vukojevic, V., Vogler, C., Milnik, A., et al. (2018) Integrated Genetic, Epigenetic, and Gene Set Enrichment Analyses Identify NOTCH as a Potential Mediator for PTSD Risk after Trauma: Results from Two Independent African Cohorts. Psychophysiology, e13288. https://doi.org/10.1111/psyp.13288

[30] Bangasser, D.A., Curtis, A., Reyes, B.A., Bethea, T.T., Parastatidis, I., Ischiropoulos, H., Van Bockstaele, E.J. and Valentino, R.J. (2010) Sex Differences in Corticotropin-Releasing Factor Receptor Signaling and Trafficking: Potential Role in Female Vulnerability to Stress-Related Psychopathology. Molecular Psychiatry, 15, 896-904. https://doi.org/10.1038/mp.2010.66 